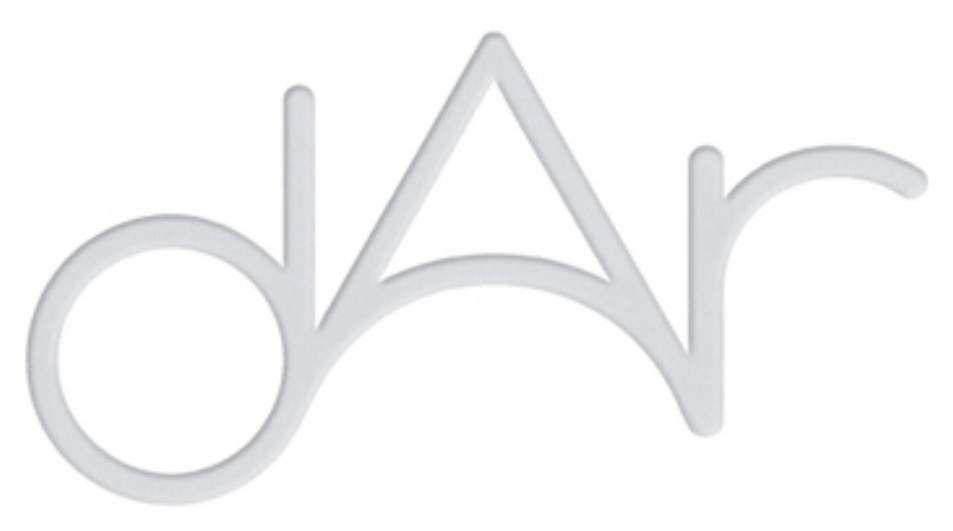

\title{
La Bóveda de Bahareque de la Iglesia de San Ignacio en Bogotá
}

Autor(es): López Pérez, Cecilia

\section{Publicado por: CEAUCP}

URL

persistente: URI:http://hdl.handle.net/10316.2/9123

DOI: $\quad$ DOI: http://dx.doi.org/10.14195/2182-844X_1_5

Accessed : $\quad$ 26-Apr-2023 11:49:53

A navegação consulta e descarregamento dos títulos inseridos nas Bibliotecas Digitais UC Digitalis, UC Pombalina e UC Impactum, pressupõem a aceitação plena e sem reservas dos Termos e Condições de Uso destas Bibliotecas Digitais, disponíveis em https://digitalis.uc.pt/pt-pt/termos.

Conforme exposto nos referidos Termos e Condições de Uso, o descarregamento de títulos de acesso restrito requer uma licença válida de autorização devendo o utilizador aceder ao(s) documento(s) a partir de um endereço de IP da instituição detentora da supramencionada licença.

Ao utilizador é apenas permitido o descarregamento para uso pessoal, pelo que o emprego do(s) título(s) descarregado(s) para outro fim, designadamente comercial, carece de autorização do respetivo autor ou editor da obra.

Na medida em que todas as obras da UC Digitalis se encontram protegidas pelo Código do Direito de Autor e Direitos Conexos e demais legislação aplicável, toda a cópia, parcial ou total, deste documento, nos casos em que é legalmente admitida, deverá conter ou fazer-se acompanhar por este aviso.

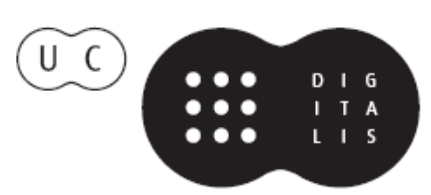


$6^{\circ}$ Seminário de Arquitectura em Terra em Portugal ( $6^{\circ}$ ATP) $9^{\circ}$ Seminário Ibero-americano de Construção e Arquitectura com Terra (9 SIACOT)

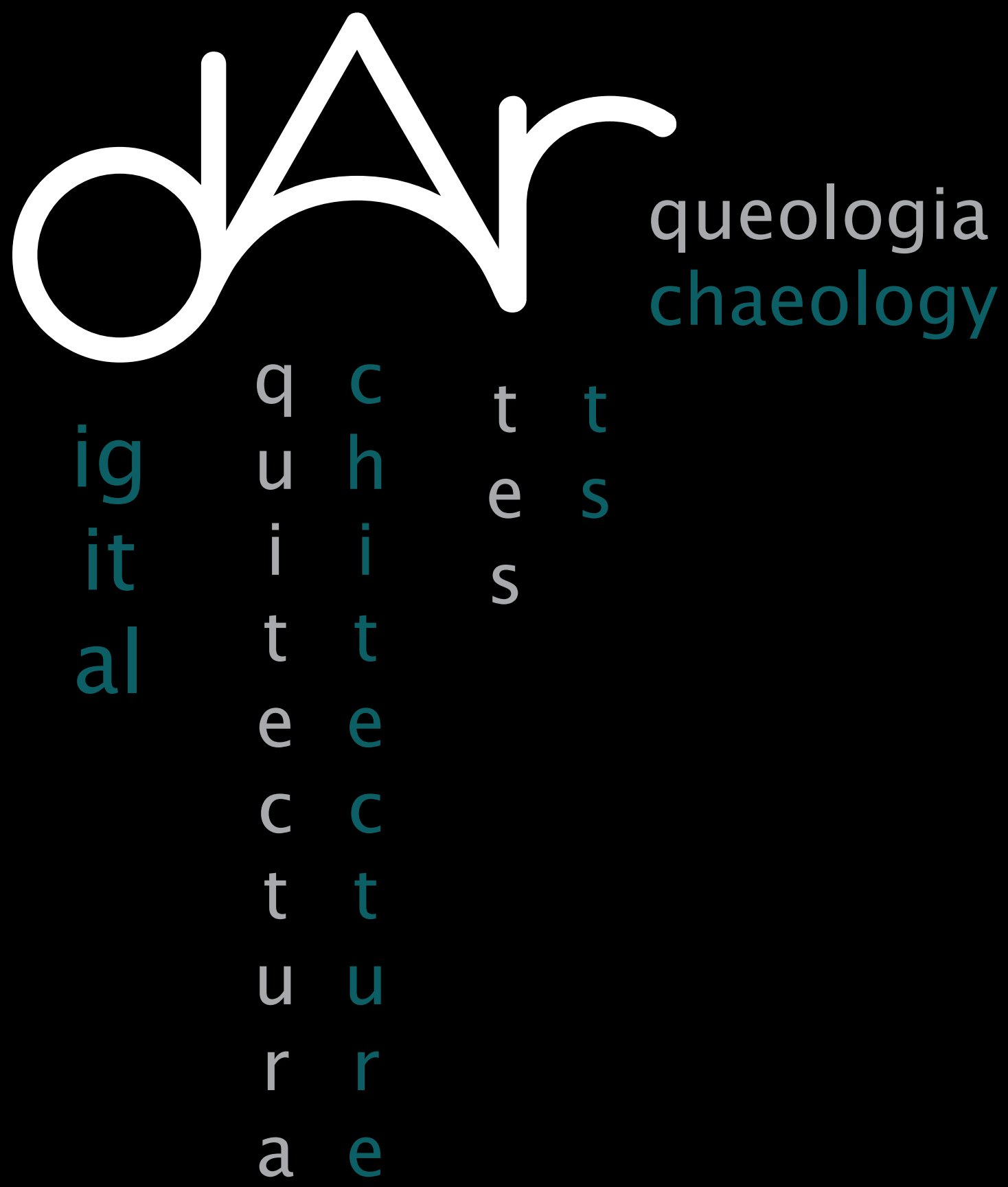




\title{
LA BÓVEDA DE BAHAREQUE DE LA IGLESIA DE SAN IGNACIO EN BOGOTÁ
}

\author{
Cecilia López Pérez* (Colombia) \\ Facultad de Arquitectura y Diseño \\ Pontificia Universidad Javeriana
}

\section{RESUMEN}

Uno de los principales propósitos que tuvieron las comunidades religiosas al llegar a nuestro territorio fue la de adoctrinar a los naturales en la nueva fe. Para facilitar esta labor se procedió a la construcción de iglesias con los materiales y técnicas que conocían los indígenas como el bahareque y dos introducidos por los ibéricos como la tapia y el adobe.

Inicialmente, las iglesias se cubrían con una estructura triangular, llamada de par y nudillo, en madera rolliza o escuadrada sobre la que se colocaba un entramado en cañas amarrado con cuero o cuan (fibra vegetal), sobre ella una capa de barro con cubierta en paja o teja de barro.

Una forma evolucionada de acabado interno de estas edificaciones se dio con la construcción de bóvedas que cubrían la nave central. Edificadas inicialmente en piedra o ladrillo colapsaron por los movimientos sísmicos que sufría nuestro continente, siendo reemplazadas por las construidas en madera ó bahareque. Las bóvedas de bahareque resultaron una solución adecuada y práctica para nuestro medio ya que por su flexibilidad soportaban mejor los sismos.

Ejemplos del desarrollo de estas bóvedas se encuentran documentadas en la costa pacífica, en el Valle del Cauca (Iglesia del Carmen y San Francisco) y la iglesia de San Ignacio en Bogotá.

La iglesia de San Ignacio en Bogotá, es una construcción realizada entre 1600 y 1661 que pertenece a la Compañía de Jesús. Es de una sola nave con capillas laterales, unidas entre sí por arcos fajones apoyados en pilares. Su planta es de cruz latina con cúpula en el crucero. Las capillas laterales están cubiertas por bóvedas vaídas que conforman diferentes espacios.

La nave central está cubierta por una bóveda de cañón con lunetos que iluminan el espacio central, tiene una longitud de 28,43 m y un ancho de 11,00 m. La bóveda está formada por seis secciones construidas con madera, cañas y fibras vegetales apoyadas en siete arcos fajones. En 1691 la iglesia sufre las primeras grietas en la cúpula desplomándose y arrastrando el tramo más cercano de la bóveda.

Estas circunstancias llevaron a que se reemplazara el tramo de la bóveda faltante en 1694, con un sistema constructivo en madera, distinto al empleado en el resto de la bóveda. Adicionalmente, la cúpula ha sido varias veces reconstruida y ha sufrido diversas intervenciones que han afectado el comportamiento de la bóveda de la nave central. Así mismo ha producido desprendimientos en los elementos que forman el intradós y deformaciones a nivel estructural.

A partir del año 2003, la Pontificia Universidad Javeriana se dio a la tarea de hacer la restauración de la iglesia; por lo cual se hizo necesario el conocimiento del sistema constructivo de la bóveda original y la parte intervenida de manera que se pudiera corregir las patologías que viene presentando.

En el presente artículo se presentara los resultados encontrados en la investigación desarrollada por el grupo GRIME (Grupo de investigación en materiales y estructuras) en esta bóveda y las recomendaciones para su intervención.

Palabras clave: Bóvedas, bahareque, sistema constructivo.

*lopez.c@javeriana.edu.co 


\section{GENERALIDADES}

Para afianzar el proceso de dominio de los territorios conquistados en Colombia, los ibéricos fundaron poblaciones que les permitieron consolidar su autoridad entre la población sometida y sus áreas de asentamiento. Es así como al llegar los españoles, a la actual zona andina, encontraron cerca de 300 caseríos de indios Muiscas, los cuales fueron reagrupados en nuevos grupos urbanos a la manera y tradición española. Mientras los conquistadores tomaban posesión de las tierras fundando poblaciones y estableciendo haciendas, los religiosos se ocupaban de adoctrinar a los indígenas en la nueva fe.

Las iglesias colombianas al igual que las europeas propiciaron el nacimiento de formas eficientes de organización social y de participación en torno a lo sagrado, que se vio reflejado en la construcción de setenta mil templos (Gil Tovar, 1983) en los tres siglos que duro la colonia. A su alrededor se generaron otros usos complementarios a la actividad religiosa como colegios, conventos, seminarios, hospicios y hospitales. Dando origen a poblaciones y desarrollos urbanos (Sornoza, Salazar, 2001, p.92).

Durante este periodo, los servicios que actualmente ofrece el estado, fueron prestados por las comunidades religiosas a través de sus misioneros, frailes y monjas dedicadas a la educación así como el cuidado de enfermos, ancianos y niños. Durante la colonia la iglesia cumplió la función de ente aglutinador de la comunidad, punto de referencia y encuentro en la vida cotidiana de la época.

Los núcleos urbanos estaban formados por el templo, la casa cural, las capillas posas y el rollo (luego cruz atrial) (Arango, Silvia, 1993, p. 62), la plaza o atrio a cuyo alrededor se edificaban las construcciones de encomenderos, capitanes y caciques de cada región. Estas poblaciones poseían disposiciones y ordenanzas que determinaban su ubicación y características tanto espaciales como formales.
Inicialmente, las iglesias se cubrían con una estructura triangular, llamada de par y nudillo, en madera rolliza o escuadrada sobre la que se colocaba un entramado en cañas amarrado con cuero o cuan (fibra vegetal), sobre ella una capa de barro con cubierta en paja o teja de barro.

Una forma evolucionada de acabado interno de estas edificaciones se dio con la construcción de bóvedas que cubrían la nave central. Edificadas inicialmente en piedra o ladrillo colapsaron por los movimientos sísmicos que sufría nuestro continente, siendo reemplazadas por las construidas en madera ó bahareque. Las bóvedas de bahareque resultaron una solución adecuada y práctica para nuestro medio ya que por su flexibilidad soportaban mejor los sismos.

Ejemplos del desarrollo de estas bóvedas se encuentran documentadas en la costa pacífica, en el Valle del Cauca (Iglesia del Carmen y San Francisco) y la iglesia de San Ignacio en Bogotá, que es una construcción realizada entre 1600 y 1661 que pertenece a la Compañía de Jesús.

\section{LAS BOVEDAS}

Un nuevo paso de acabado interno de los templos, se dio con la construcción de bóvedas. Estas se construían en madera rolliza o escuadrada las cuales cubrían la nave central o las capillas anexas a la nave principal y se decoraban con elementos en yeso o madera. Paralela a estas se desarrollaron las construidas en bahareque. Las bóvedas de bahareque resultaron una solución adecuada y práctica para nuestro medio ya que por su flexibilidad soportaban mejor los sismos.

\subsection{Bóvedas en madera}

Las bóvedas de cañón en madera son aquellas que mantienen su obra de fábrica arqueada, formando un techo o cubierta en este material. Su construcción se basó en los cánones establecidos en el tratado de Sebastinao Serlio, Philibert D'Lorme el alarife Diego López de Arenas, el fraile Andrés de San Miguel y el maestro Rodrigo 
Alvarez. Ejemplo de este tipo de bóvedas se encuentran en España realizadas por los Agustinos Descalzos como la Capilla del Desamparo de Cristo en el Convento de Madrid; en la Ermita de Nuestra Señora del Prado en Talavera y en el Convento de los Agustinos Descalzos en Salamanca.

En Latinoamérica, se encuentran en Méjico en el templo y ex convento del Carmen en el Distrito Federal. En Brasil, en el Colegio de los Jesuitas (hoy catedral de Bahía) (Segre, 2009) y en el convento de San Francisco de la misma ciudad. En Ecuador, en la iglesia de San Francisco en Quito (Navarro, 2009) y en Bolivia la Catedral Metropolitana de Santa Cruz de la Sierra.

En Colombia, en el centro histórico de la capital se han referenciado ocho bóvedas como sistema constructivo para cubiertas, bóvedas y cúpulas. Esta técnica parte de una estructura de madera o cañas que se trenzan formando una membrana extendiendo sobre las caras laterales un recubrimiento en barro, cal o yeso mezclado con agua. Este sistema se emplea actualmente en países como Perú, Bolivia, Ecuador y Chile denominado quincha y fajina en Uruguay (Arbelaez Camacho, 1967, pp. 270-271).

En Colombia, se han encontrado bóvedas con este sistema en el Valle del Cauca en la Iglesia del Carmen y San Francisco. La iglesia del Carmen de Popayán presenta amarres en cuero y la de San Francisco está formada por camones, y entramado en caña brava con una capa de barro (Archivo Dirección de Patrimonio).

\begin{tabular}{|c|c|c|}
\hline \multicolumn{3}{|c|}{ IGLESIAS } \\
\hline TIPO IGLESIA & ORDEN & BOVEDA \\
\hline Iglesia de Santa Clara & Clarisas & $\mathrm{X}$ \\
\hline Iglesia de La Concepción & Capuchinos & $\mathrm{X}$ \\
\hline $\begin{array}{c}\text { Santuario Nuestra Señora del } \\
\text { Carmen }\end{array}$ & Salesianos & $\mathrm{X}$ \\
\hline San Agustín & Agustinos & $\mathrm{X}$ \\
\hline La Candelaria & Agustinos Recoletos & $\mathrm{X}$ \\
\hline San Ignacio & Jesuitas & $\mathrm{X}$ \\
\hline Ermita de la Tercera & Franciscanos & $\mathrm{X}$ \\
\hline San Juan de Dios & $\begin{array}{c}\text { Orden hospitalaria de } \\
\text { San Juan de Dios }\end{array}$ & $\mathrm{X}$ \\
\hline
\end{tabular}

Tabla 1. Iglesias menores que tienen bóvedas en el centro histórico de Bogotá construidas en madera (Tabla 1) y la cúpula de la Iglesia Mayor de Villa de Leyva construida con el mismo material.

\subsection{Bóvedas en bahareque}

Sobre el uso del sistema de bahareque en bóvedas, sólo se han encontrado referencias a nivel latinoamericano. El bahareque, es un sistema constructivo de origen prehispánico el cual es una mezcla de madera, cañas y tierra usado en muros y cerramientos.

A esta técnica se le ha denominado quincha, bajareque o bahareque a nivel latinoamericano (Instituto Eduardo Torroja, 1986) para en paredes, tabiques, columnas, pilastras, arcos y torres sino
Adicionalmente deben incluirse también las iglesias de San Ignacio en Tunja y Bogotá. La Iglesia de San Ignacio en Tunja fue desmontada entre 1969 y 1971 en la intervención de Acevedo Quintero quien considero que la bóveda y el crucero eran agregados de la edificación razón por la cual actualmente no existen.

\section{LA IGLESIA DE SAN IGNACIO}

\subsection{Localización y descripción}

arquitectónica

La Iglesia de San Ignacio (Fig. 1) se localiza en la calle 10 con carrera 6 en Bogotá. Está conformada por una sola nave con capillas laterales, unidas entre sí por arcos fajones 
apoyados en pilares. Su planta es de cruz latina con cúpula en el crucero. La cubierta

a

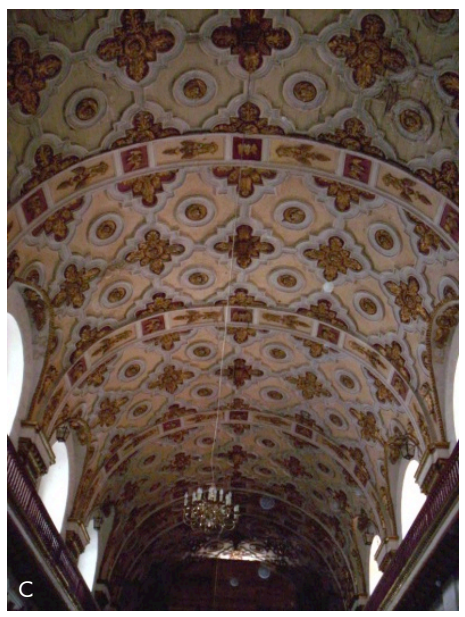

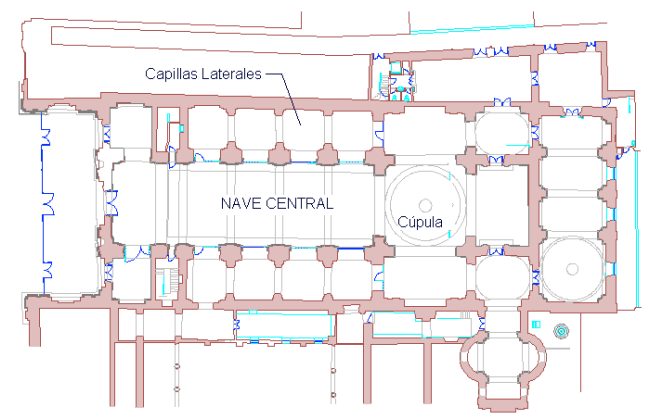

occidental de la fachada se encuentra la torre, donde están las campanas. En
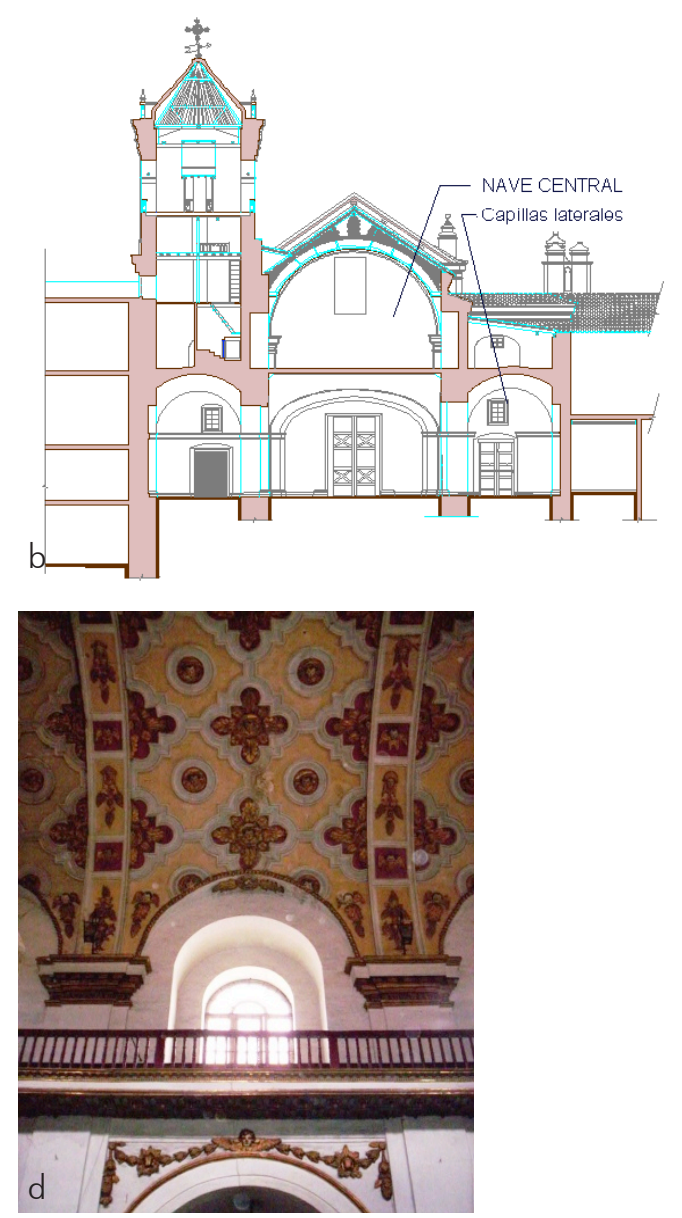

Fig. 1. (a) Planta; (b) corte de la iglesia de San Ignacio; (c) Vista de la bóveda; (d) Luneto (Fuente: Instituto Carlos Arbeláez Camacho y autores)

de la nave es una bóveda de cañón, con lunetos que iluminan el espacio central. La bóveda tiene una longitud de $28,4 \mathrm{~m}$ y un ancho de 11,0 m. Las capillas laterales están cubiertas por bóvedas vaídas que conforman diferentes espacios (Arbeláez Camacho, 1967, pp. 270-271).

La fachada presenta una distribución clásica (Renteria Salazar, 2001, p. 16) diferente a la que hasta la época se empleaba. Es simétrica, diseñada con dos torres de la cual sólo se construyó una. Su composición posee elementos horizontales (cornisas) y verticales (pilares o columnas dobles) que forman tres cuerpos. Entre las dos columnas hay tres nichos que no poseen ninguna imagen. Al costado

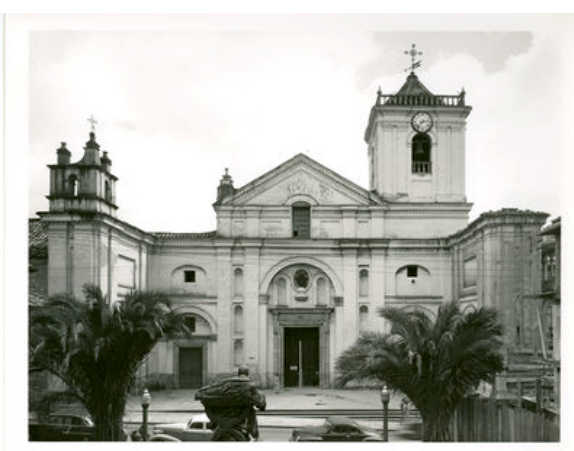

Fig. 2. Iglesia de San Ignacio (Fuente: Arquidiócesis de Bogotá)

el cuerpo central se halla una puerta de madera de dos hojas, aldabas y botones 
en bronce, se remata este cuerpo con un frontón moldurado.

\subsection{Evolución constructiva}

La primera referencia sobre la construcción de la iglesia se encuentra en el año 1610, cuando bajo la dirección del padre Coluccini se inicia la construcción. Luego para 1611 y 1612, se documenta la finalización de la cimentación y la aparición de los primeros muros (Rentería Salazar, 2001, pp. 102-103).

Durante este periodo fue un activo colaborador de la obra el padre Pedro Pérez. En 1585 Pérez había trabajado como ensamblador y superintendente de las obras de la iglesia de Córdoba-España, donde estuvo laborando hasta 1607, luego se traslado a la Nueva Granada en Mayo de 1612 (Renteria Salazar, 2001, p. 105). El padre Pérez vivió y colaboró con Coluccini en la construcción (Rentería Salazar, 2001, p. 102) En 1611 se reportó que hasta antes de la llegada del padre Pérez se respetò la traza original de la cimentación, pero cuando el llegó hubo cambios volumétricos en los arcos, bóvedas, en las alturas y en los espacios que se abrían hacia la nave central (Rentería Salazar, 2001, p. 111)

Para 1616, el padre Manuel de Arceo comentaba sobre lo suntuosa que era la edificación. Estaban construidos los arcos de la iglesia y una de las capillas laterales estaba terminada. La construcción continua, pero dos de los cuatro arcos torales se vinieron abajo y tuvieron que ser reconstruidos para continuar con la obra. Para 1620 se suspende la obra (Pacheco, 1989, p. 112).

La obra reinicia trabajos en 1627 y para 1635, el templo fue consagrado y dedicado a San Ignacio, fundador de la orden Jesuita. Pero faltaban por construir la capilla mayor, el crucero y la cúpula.

Entre el año 1639 y 1690, se da el inicio a la venta de capillas empleadas como mausoleos para familias. Para 1691, el templo se encontraba completo. Durante este año se presentó un temblor que averió la cúpula. Según lo relata el padre Pacheco el 23 de Abril de 1691 se vino abajo la mitad de la cúpula cayéndose el primer tramo de la bóveda de bahareque. El hermano Juan Bautista Milán llegó de Italia para dirigir la reconstrucción de la obra quedando terminada tres años después (Pacheco, 1989. Capitulo VIII, p. 120).

En el terremoto del 18 de Octubre de 1743, quedo la cúpula nuevamente deteriorada, por lo cual fue necesario descargarla para su reconstrucción. El 10 de Septiembre de 1763, vuelve a caerse la cúpula. En 1800, el virrey Pedro Mendinueta advierte que es necesario la reconstrucción de la cúpula, para ello comisiona a Bernardo Anillo quien diagnostica que no es necesario descarga la cúpula sino ceñirle una cadena de hierro de forma perimetral (Pacheco, 1989, pp. 383-384). En 1804, el padre Fray Domingo de Petres la reconstruye de nuevo, siendo la cúpula actual. En 1975, mediante el Decreto 1584 se declara el templo como monumento nacional.

\subsection{Sistema constructivo}

El sistema estructural es en mampostería realizado con técnica mixta de piedra y ladrillo cocido, el espesor aproximado es de 1,75 cm. Los pilares son macizos en ladrillo cocido. Los entrepisos en el coro y los corredores de laterales de la nave central son en madera. Se encuentran en regular estado de conservación por falta de mantenimiento. Los pisos son en arcilla cocida y tableta de cemento

La cubierta es a dos aguas en la nave central, formando una estructura triangular. La estructura es de madera, rolliza de pares y tirantes, con un diámetro aproximado de $15 \mathrm{~cm}$, apoyadas sobre los muros. Sobre esta estructura hay un entramado en chusque, amarrado con cuan trenzado, sobre esta se encuentra una torta de barro.

Como acabado final de cubierta, en la nave central, se encuentra la teja de barro. Sobre el sector oriental, que colinda con el Museo de Arte Colonial, se sustituyó el chusque por teja Onduline. Este sistema ha provocado deslizamientos de las unidades de teja de barro, provocando filtraciones en las áreas internas de la cubierta y 
pudrición en los elementos que conforman la estructura.

Como elementos complementarios a la cubierta se encuentran las canales metálicas que fueron parcialmente sustituidas en 1998. Esta instalación fue mal realizada por lo cual se empezaron a presentar filtraciones en los muros del costado occidental. Estos fueron sustituidos junto con la cubierta total en los años 20062007.

Interiormente, se conserva el altar mayor, desarrollado por Diego Loessing. Adicionalmente se encuentra imaginería, tallas y pintura de caballete en diferentes altares de los siglos XVII y XVIII de diferentes autores como: Gregorio Vázquez, los Figueroa, Antonio Acero de la Cruz y Pedro Laboria.

\subsection{La bóveda de San Ignacio}

La bóveda (Fig. 3) que cubre la nave central es de cañón con una altura aproximada de $5,5 \mathrm{~m}, 11,0 \mathrm{~m}$ de ancho y $28,43 \mathrm{~m}$ de longitud, construida en madera, caña, barro y cal. Los ornamentos son tallados en madera. Está formada por seis tramos y siete arcos formeros, que tienen de ancho de $5 \mathrm{~m}$ a $6 \mathrm{~m}$, excepto el tramo 2 que tiene un ancho de 1,70 m.

Los tramos 1 a 5 son los más antiguos construidos en bahareque y el 6 por el colapso de la cúpula es de manufactura distinta (madera) y más reciente que los otros cinco.

\subsubsection{Bóveda de madera}

La bóveda (Fig. 4) ubicada a lo largo de la nave central se apoya en las cornisas de los muros de mampostería perimetrales. La estructura portante está formada por costillares constituidos por la unión de piezas de madera (camones). El intradós o cara interna de la bóveda se forma con planchones de madera de 0,15 m x 0,025 m. Los lunetos o ventanas que iluminan la nave se forman igualmente con planchones. La cara interna está decorada con elementos de yeso o madera, con motivos florales o poliformes.

\subsubsection{Bóveda de bahareque}

\subsubsection{1.}

Elementos de los tramos 1 a 5 Los tramos 1 a 5 están formados por los siguientes elementos (Fig. 5):

a) Costillares, que es la estructura de madera formada por camones.

b) Camones: pequeñas piezas de madera traslapadas entre sí que forman un costillar.

c) Tensores: Elementos de madera que unen los costillares con las vigas de cubierta.

d) Chusque: Caña delgada que forma la curvatura de la bóveda en los tramos más antiguos.

e) Cuan: Fibra de origen vegetal que sirve de amarre.

f) Argamasa: Barro y cal, que sirve de unión de todos los elementos.

g) Ménsulas: Sirven de apoyo a la bóveda. Tienen una sección de $20 \mathrm{x}$ 20, empotradas al muro portante que conforman la nave central. 

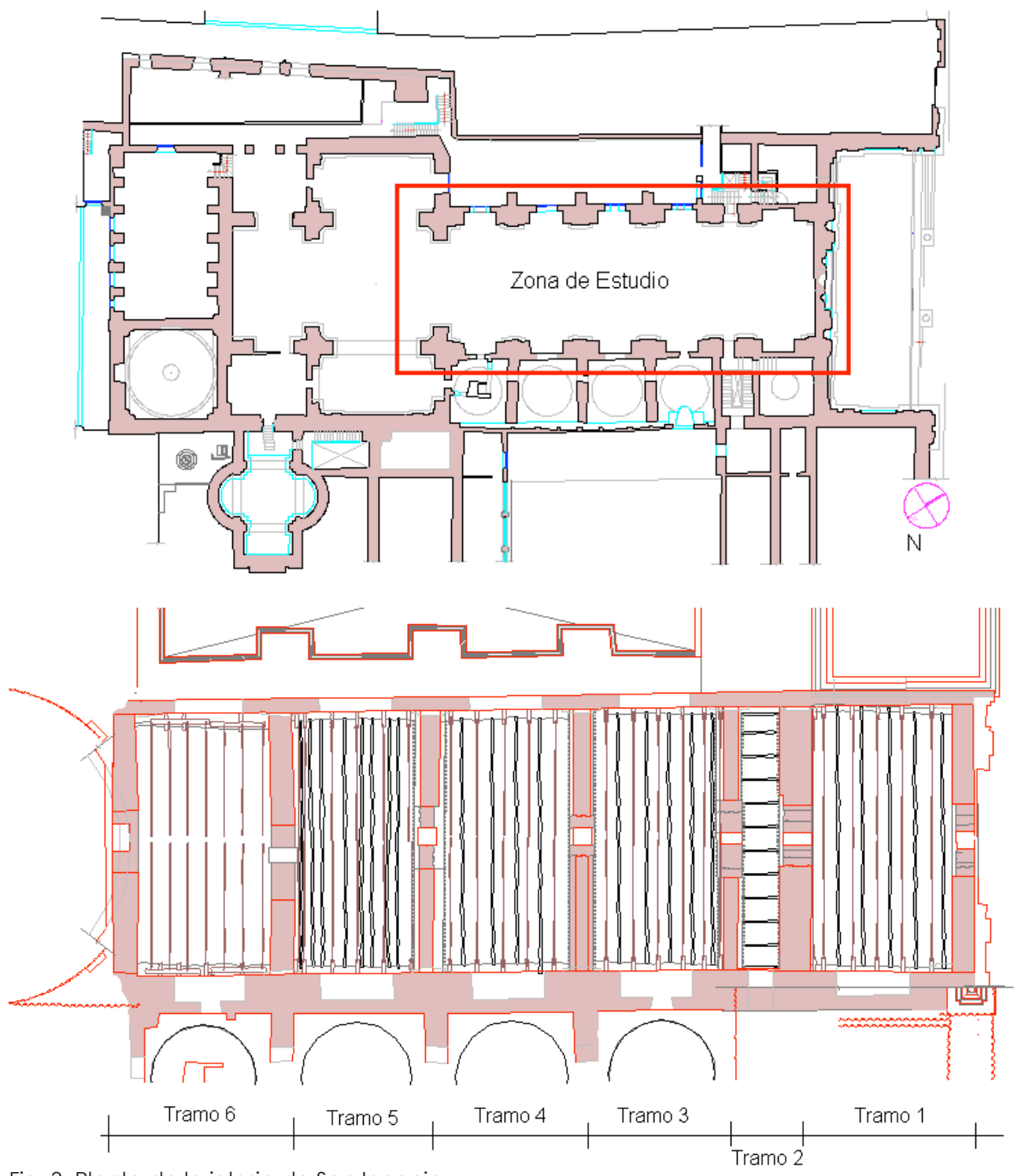

Fig. 3. Planta de la iglesia de San Ignacio 

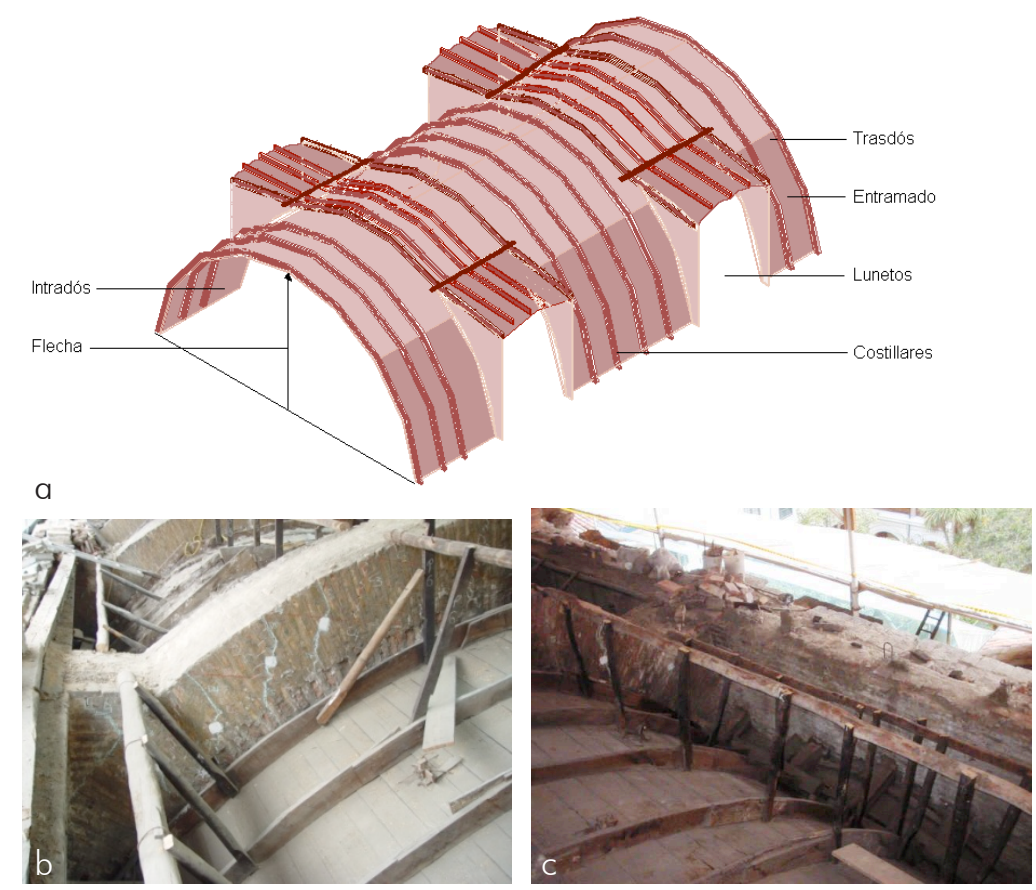

Fig. 4. (a) Elementos que forman la bóveda de madera; (b) y (c) Imágenes de la bóveda en madera
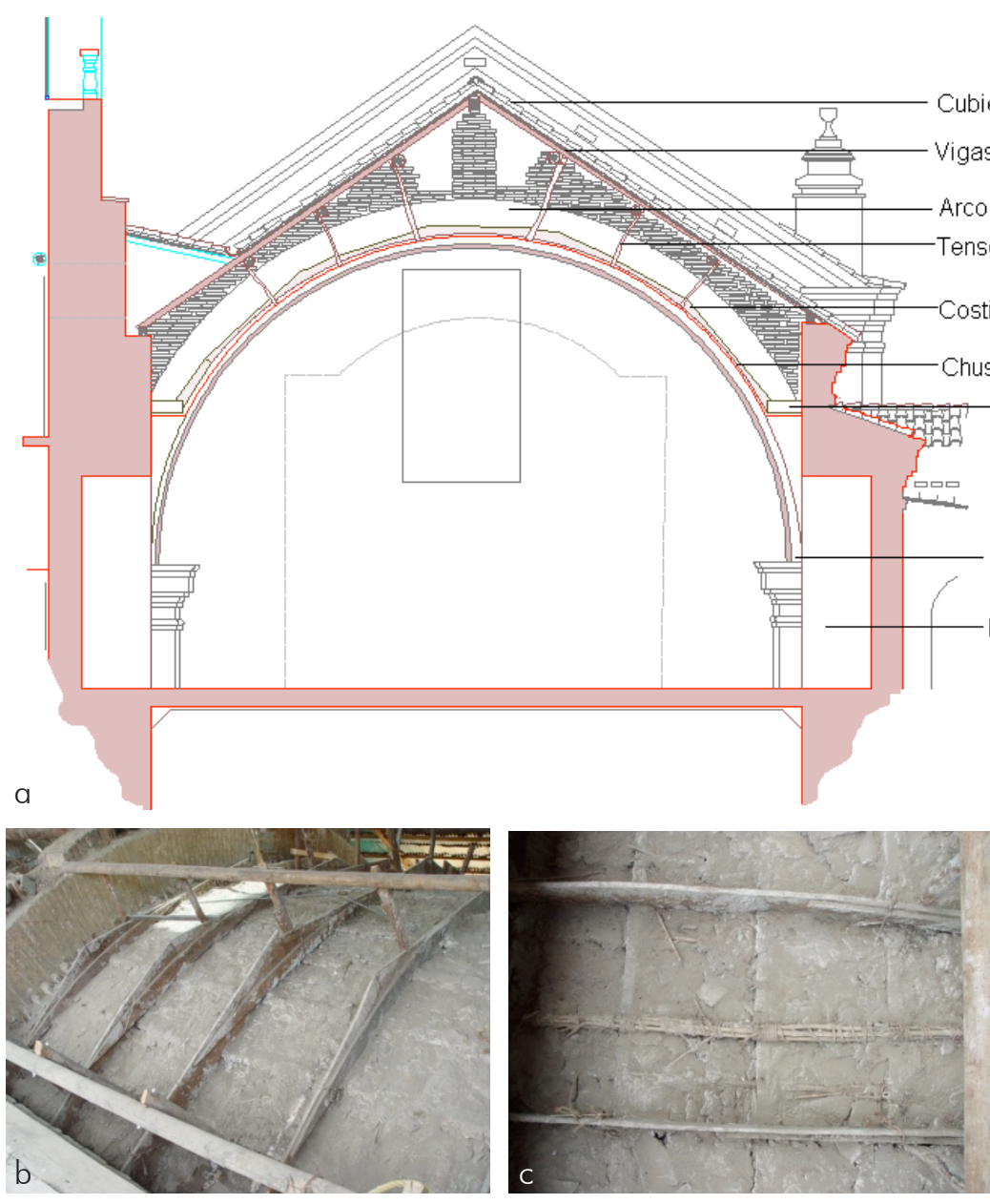

Fig. 5. (a) Elementos que conforman la bóveda de bahareque; (b) y (c) Imágenes de la bóveda de bahareque 


\subsubsection{Sistema constructivo}

La estructura está formada por:

a) Siete arcos formeros en ladrillo que tienen la parte superior dentada.

b) Se colocan piezas (durmientes) de 5 $\mathrm{cm}$ de alto por $2,5 \mathrm{~cm}$ de ancho de madera que van de arco a arco formero apoyados sobre la parte dentada del arco (pieza A). Estas piezas sirven de soporte a los costillares y cumplen una función estructural, ya que evitan su desplazamiento.

c) Se arman los costillares con camones de 0,25 $\mathrm{m}$ a 0,30 $\mathrm{m}$ de altura, una longitud de $2,10 \mathrm{~m}$ a $2,50 \mathrm{~m}$ y traslapos aproximados de $0,45 \mathrm{~m}$ (pieza B). A los camones se les dejan pases o huecos por donde se pasa la pieza que va apoyada en la parte dentada (pieza A). Los costillares tienen una distancia entre

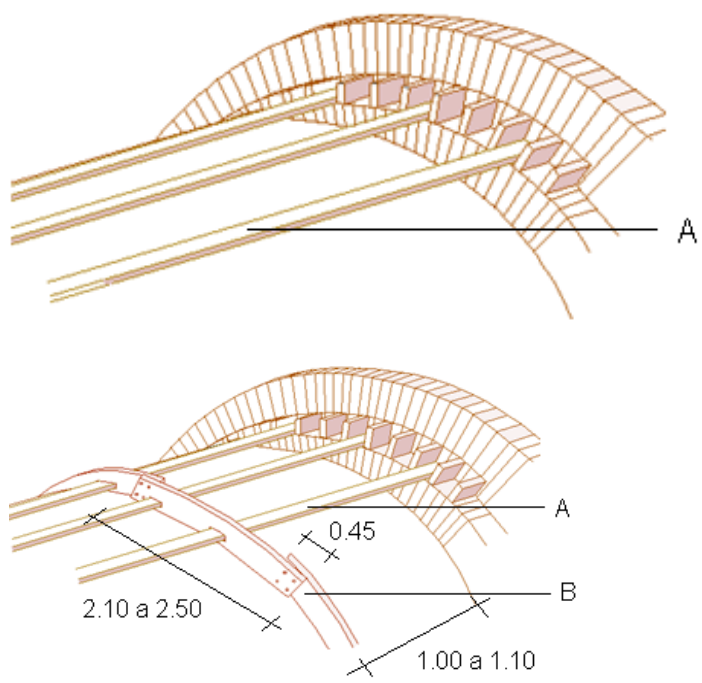

sí de 1,00 $\mathrm{m}$ a 1,10 m.

d) Se forman manojos de 8 chusques(1), amarrados con cuan(2). La longitud del manojo es de 6,10 a 6,30, con traslapo entre manojos de 1,10 a 1,30.

e) Se amarra a la pieza A la primera capa de manojos de chusque, trenzándolos (pasan por encima o por debajo de la pieza A) dejando un espacio de $0,40 \mathrm{~cm}$ a $0,60 \mathrm{~cm}$ aproximadamente (pieza C).

f) A la pieza $C$, se amarra en sentido perpendicular el cañizo formado por chusque amarrado con cuan uno junto al otro. Este cañizo distribuye los esfuerzos
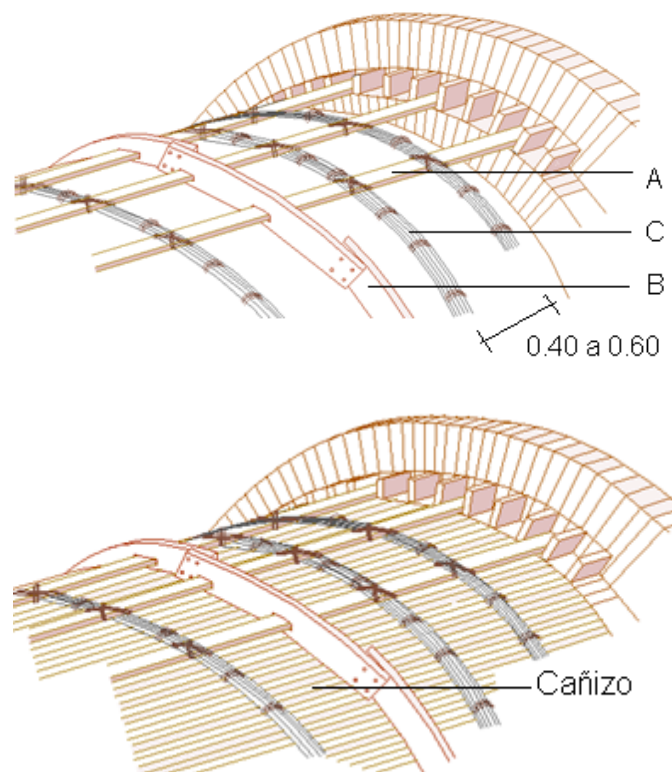

hasta la base de apoyo en las ménsulas.

g) Se coloca sobre el cañizo una lechada de argamasa (tierra-cal) que forma en el intradós de la bóveda una capa rugosa.

h) Por el extradós, y sobre la pieza A, se coloca y amarra con cuan la segunda capa de manojos de chusque (pieza

D). Este debe ir traslapado al manojo de
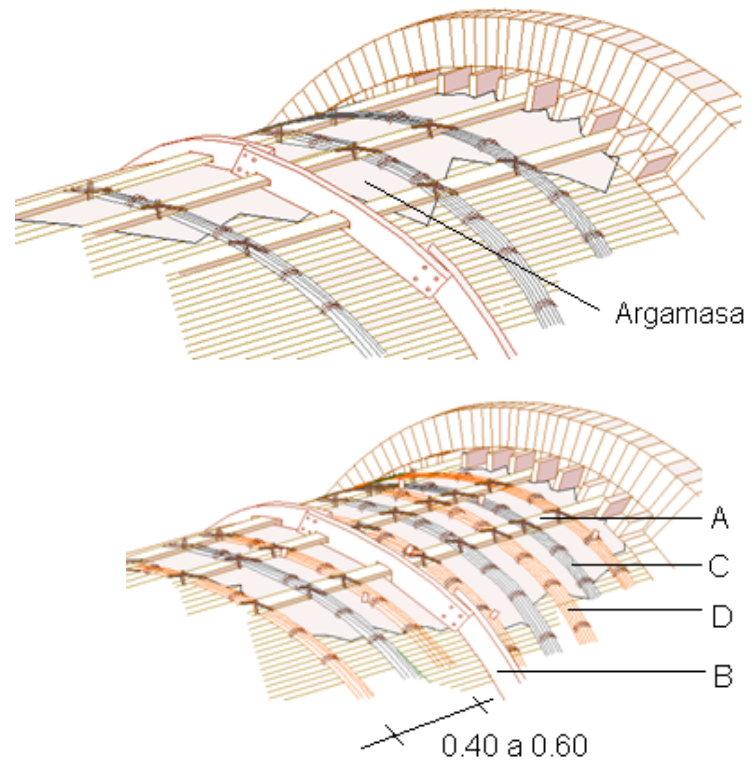

abajo, en distancias similares.

i) Paralelo al manojo o pieza D, se coloca un cañizo formado con chusque (pieza E).

j) Sobre esta pieza se coloca una argamasa que es una mezcla de tierra y cal que cubre y protege todas las piezas 


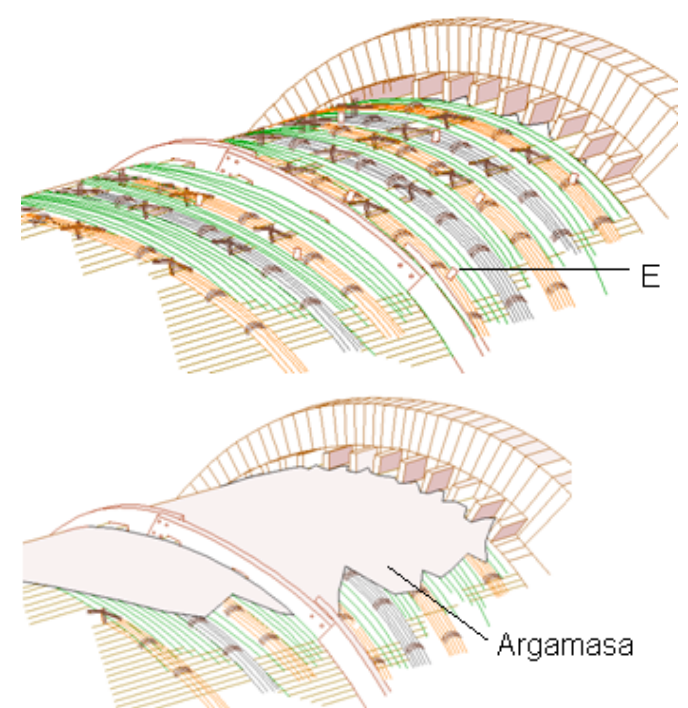

que se encuentran en el extradós.

k) Toda esta estructura está colgada de las vigas que forman la cubierta mediante tensores de madera fijados con clavos de forja. En algunos casos se encontraron amarres adicionales con cuan.

\subsubsection{Acabado}

En el intradós sobre la superficie rugosa formada por la lechada se colocaba un lienzo y sobre él se aplicaba el pañete de acabado con yeso. Finalmente, se
Iuz de los análisis realizados estos tensores no tienen una gran responsabilidad estructural para las cargas de trabajo.

\section{PATOLOGIAS ENCONTRADA}

En San Ignacio la cúpula sobre el altar colapsó, arrastrando el tramo más cercano de la bóveda (tramo 6); por lo cual, tuvo que ser reemplazada con una bóveda en madera. Sin embargo, las maderas empleadas en esta intervención no poseían la inmunización ni el tratamiento adecuado por lo que este sector, ha empezado a afectar los otros tramos ( 1 al 5) de la bóveda original.

\section{CONCLUSIONES}

Una forma particular de acabado interno de las iglesias se dio mediante la construcción de bóvedas en madera y bahareque en diferentes regiones de nuestro territorio. Las dos tienen componentes constructivos y comportamientos estructurales diferentes. En San Ignacio, se encontraron dos sistemas constructivos uno en bahareque y el otro en madera.

Las bóvedas de bahareque por considerarse de inferior calidad han sido desmontadas desconociendo las propiedades estructurales que el sistema

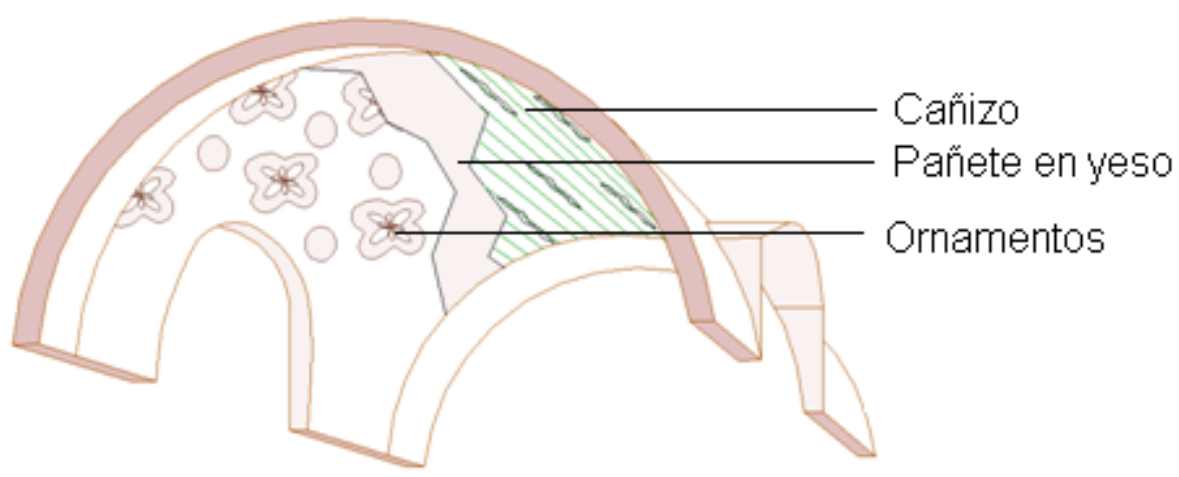

instalaban las piezas y ornamentos de madera que tienen un pin o pata de anclaje que se amarra al extradós de la bóveda.

Para sostener toda esta estructura existen unos tensores, que se colocan para sostener los camones en el momento de su construcción, y van desde los camones hasta las correas o vigas. En principio, y a la

de bahareque posee. Lo que hace necesario, que quienes tienen a su cargo la intervención de este tipo de edificaciones analicen, ojala en grupos interdisciplinarios de estudio, todas las variables constructivas de estos sistemas con el objeto de realizar restauraciones que se ajusten no sólo a los requerimientos estéticos, sino tengan en cuenta las características estructurales. 

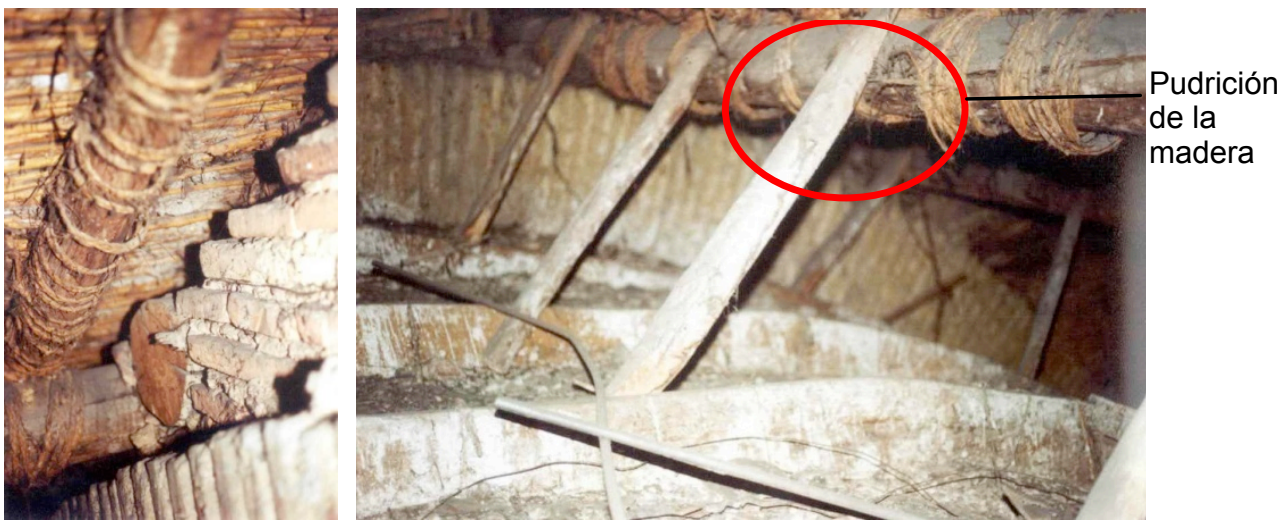

Fig. 6. (a) deterioro de los amarres y (b) pudrición de las vigas

\section{Bibliografía}

Arango, S. (1993). Historia de la arquitectura en Colombia. Universidad Nacional de Colombia.

Arbeláez Camacho, C., López, S. (1967). La Arquitectura Colonial. Historia Extensa de Colombia. Bogotá: Ed. lerner.

Gil Tovar, F. (1983). Historia del arte colombiano. Volumen VI. Barcelona: Salvat editores.

Instituto Eduardo Torroja (1986). Informes de la Construcción. Vol. 37 (no. 377).

Pacheco, J. M. (1989). Los Jesuitas en Colombia: capitulo XV, los templos jesuíticos. Bogotá D.E: oficina de publicaciones de la Pontificia Universidad Javeriana.

Pacheco, J. M. (1962). Los Jesuitas en Colombia: Las primeras fundaciones. Tomo I y II. Bogotá: Editorial San Juan Eudes.

Rentería Salazar, P. (2001). Arquitectura en la Iglesia San Ignacio de Bogotá. Modelos influjos, artífices: Coluccini, arquitecto de la iglesia de San Ignacio Bogotá. Bogotá: Editorial Ceja.

Sornoza Salazar, R. (2001). Papel del espacio urbano en el fortalecimiento de la conciencia de lo público. Revista Palabra clave, no. 4.

Agradecimientos

La autora desea agradecer la colaboración de la Vicerrectoría Académica de la Pontificia Universidad Javeriana por la financiación del proyecto "Análisis de bóvedas hechas en madera en templos coloniales bogotanos").
Notas

(1) Caña delgada de la familia del bambú

(2) Fibra vegetal que se obtiene en los lagos. Se teje formando cordones y trenzas con los que se amarra 